\title{
Effect of Volatility Changes on Emerging Stock Markets: The Case of Jordan
}

\author{
Dr. Marwan Mohammad Abu Orabi \\ The World Islamic Sciences \& Education University, Amman, Jordan \\ P.O. Box: 1101, Postal Code: 11947 Amman \\ E-mail: Drmarwan1974@yahoo>com \\ Dr. Talal Abed-Alkareem Alqurran \\ The World Islamic Sciences \& Education University, Amman, Jordan \\ P.O. Box: 1101, Postal Code: 11947 Amman \\ E-mail:tqurran@yahoo.com
}

Received: April 6, 2015

doi:10.5296/jmr.v7i4.7463
Accepted: July 1, $2015 \quad$ Published: July 1, 2015

URL: http://dx.doi.org/10.5296/jmr.v7i4.7463

\begin{abstract}
The Middle East financial markets have experienced several unexpected volatility shifts during the last two decades had recorded a serious impact on these markets and caused a financial turmoil that has elevated the uncertainties in the region. In view of this, more empirical findings should be learned and documented for future benefits. As one of the affected countries, Jordan was chosen as a case to provide empirical insight on the matter. This paper analyzed the behavior of Jordan's stock market (Amman Stock Exchange, ASE) during the intervals of high uncertainty. It highlighted the impact of volatility on this market in terms of its efficiency and returns, during 2004-2012 periods, by utilizing the iterated cumulative sums of squares (ICSS) algorithm, GARCH and GARCH-M models. Sudden changes in volatility seem to arise from the evolution of emerging stock markets, exchange rate policy changes and financial crises. Evidence also reveals that when sudden shifts are taken into account in the GARCH models, the persistence of volatility is reduced significantly in every series. Research results provided significant empirical evidence for positive risk-return relationship in the stock exchange. Moreover, this study also found that the stock market, across all sectors, was more sensitive to global news events as compared to
\end{abstract}


the local events. The asymmetrical responses to good and bad news were also an important characteristic of the ASE market behavior.

Keywords: Market Efficiency, GARCH- Model, GARCH- M Model, ICSS Algorithm Test JEL classification: G14, G15; F17, F14 


\section{Introduction}

Many investors realize that the stock market is a volatile place to invest their money. The daily, quarterly and annual moves can be dramatic, but it is this volatility that also generates the market returns investors experience. Volatility refers to the amount of uncertainty or risk about the size of changes in a security's value. Statistically it is the measure of the dispersion of returns for a given security or market index. Volatility can either be measured by using the standard deviation or variance between returns from that same security or market index. Commonly, the higher the volatility, the riskier the security is. In general, it increases when the market is bearish and decreases when the market is bullish. This is due to the common belief that bearish markets are more risky than bullish markets. There is a strong relationship between volatility and market performance. Volatility tends to decline as the stock market rises and increase as the stock market falls. When volatility increases, risk increases and returns decrease (Parasuraman, N, and Janaki Ramudu,P,2011). Crestmont examined the historical relationship between stock market performance and the volatility of the market. For this analysis, Crestmont used the average range for each day to measure the volatility of the Standard \& Poor's 500 Index (S\&P 500) index. Their research tells us that higher volatility corresponds to a higher probability of a declining market. Lower volatility corresponds to a higher probability of a rising market (Crestmont, 2011). Factors Affect Volatility include region and country economic factors, such as tax and interest rate policy, they contribute to the directional change of the market and thus volatility. For example, in many countries, the central bank sets the short-term interest rates for overnight borrowing by banks. This change of overnight rate can cause stock markets to react, sometimes violently. Changes in inflation trends influence the long-term stock market trends and volatility. Expanding price-earnings ratios $(\mathrm{P} / \mathrm{E}$ ratio) tend to correspond to economic periods when inflation is either falling or is low and stable. This is when markets experience low volatility as they trend higher. On the other hand, periods of falling $\mathrm{P} / \mathrm{E}$ ratios tend to relate to rising or higher inflation periods when prices are more unstable. This tends to cause the stock markets to decline and experience higher volatility. Industry and sector factors can also cause increased stock market volatility. For example, in the oil sector, a major weather storm in an important producing area can cause prices of oil to jump up. As a result, the price of oil-related stocks will follow suit. This increased volatility affects overall markets as well as individual stocks. Volatility works well to help identify market bottoms based on high volatility. For long-term investors, it also does a pretty good job of helping to identify that the stock market is at or near a top, when volatility is very low. It is worth to note that this indicator is not intended to time the exact top, but rather that the volatility of the market does not stay substantially below the mean for a long period of time. As the volatility increases, then the market's performance will tend to decrease.

Generally, emerging stock markets are characterized by high volatility. The Middle East financial markets have experienced several unexpected volatility shifts during the last two decades, for example, the eruption of the first and second Gulf Wars caused macro-economic and financial turmoil had elevated the uncertainties in the region(Hammoudeh, S., \& Li, H. 2008).And as theory suggests that structural changes in macroeconomic fundamentals are 
associated with the changes in the behavior of stock markets, since stock prices theoretically reflect expectations of future dividends, interest rates and risk premia, which in turn depend on the macroeconomic conditions(Morana and Beltratti, 2002).

\section{Literature Preview}

Although there is a general consensus on what constitutes stock market volatility, there is far less agreement on the causes of changes in the stock market volatility (Mala and Reddy, 2007). Engle and $\mathrm{Ng}$. attribute arrival of new and unanticipated information as the key cause for the volatility (Engle and $\mathrm{Ng}, 1991$ ). Other researchers attribute volatility to the changes in trading volumes and pattern driven by the changes in macroeconomic policies, shift in investor tolerance of risk and increased uncertainty as a cause for volatility. In addition, political changes, civil security situation and global events are also cited as causes of return volatility. The volatility in the stock return is often explained based on the time span. Long-term volatility is mainly caused by financial leverage, operating leverage and state of the economy (Schwert, 1990). Returns on shares of highly leveraged firms, Firms with a considerable amount of fixed costs, and Macroeconomic performance of the economy have impact on the long-term volatility; in addition to the above factors there are certain factors which influence stock volatility in the short-term. Attempts by many people to trade simultaneously in the same direction (either to buy or sell) cause volatility in the market (Schwert, 1990). Volatility is considered highly persistent if a shock to a given system is permanent, and the past volatility can be used in constructing forecasts of future volatility. However, tranquil periods where prices are more or less stable could be followed by relatively high volatility periods characterized by large price changes due to economic, political and/or social events, both regionally or globally. The housing burst in the US has led to a sequence of economic repercussions in the US and was transmitted to other world economies, engulfing many developed and emerging economies. The shock originated from the housing sector affected the financial sector severely as many of the insurance and investment companies dealing with the real estates and debts suffered severe financial losses on account of falling housing prices and loan defaults. The losses dragged them to go bankrupt and to close their business. The attention of the policy makers got diverted from averting overheating of the world economies in the beginning of the 2007 to averting slowdown in the economies. The stock market activity is one of the principal activities in the corporate world among the chain of activities, which got affected due to the financial crisis. The stock market indices were the principal indicators of the economic activities. The movement of stock market indices presents the future economic outlook. A falling stock index reflects the dampening of the investment climate while a rising stock index indicates more confidence and soundness of the economy. The latter attracts more investment demand on stocks. Rising investment on stocks raises sock prices and generates profits. Emerging Market Economies(EME) have undergone significant transformations with the liberalization measures. EME were engaged in various bilateral trade and economic cooperation agreements with several countries and regional groups across Asia, Europe and the Western hemisphere. In this context, the concerns regarding its exposure to risk in case of the global crisis are compelling. The analysis contained in the IMF's Global Financial Stability Report, 
(October 2008) finds that correlation of equity markets in EMEs with those in the advanced economies has risen, suggesting a growing transmission channel for equity price movements (IMF, 2008). Sudden changes in uncertainty, or volatility which might be caused by global crises should be given substantial concern as they can be persistence and have serious impact on asset prices as well as economic fundamentals. In view of this, we have surveyed the related literature, and found out that although the studies on the 1997-Asian-financial crisis and 2007, global financial crisis were extensive. Studies pertaining to the effect of sudden changes in volatility on the efficiency of Asian emerging stock market during the two crises were scarce and did not receive much attention. Time varying volatility of stock returns has been extensively modeled by the GARCH with high frequency stock data to find high persistence in volatility. The GARCH approach assumes that there is no shift in volatility; however, in such emerging markets there may potentially be sudden shifts in volatility. It is therefore important to take into account these shifts in estimating volatility persistence.

In this paper, the shifts in volatility are identified by utilizing the iterated cumulative sums of squares (ICSS) algorithm (Rajesh,T, 2010). The ICSS endogenously identifies changes in volatility of stock returns. Studies on emerging stock markets were conducted and empirical results indicated that sudden changes in volatility seem to arise from the evolution of emerging stock markets in earlier periods(Poshakwale, S., Murinde, V., 2001).It has been a well known fact that understanding the behavior of stock market volatility is important to both policy-makers and market practitioners. Policy-makers are mainly interested in the main determinants of volatility, its spillover effect on real economic activity and for assessing regulatory proposals to restrict international capital flows. On the other hand, Market practitioners, are mainly interested in the direct effects of time-varying volatility on the pricing of financial assets and hedging strategies. It is now widely noted that time-varying properties of the volatility of financial asset returns, which were conventionally measured by their variances and co variances, are no more constant over time; instead they evolve over time. Thus the assumption of constant variances over time is no longer valid (Bollerslev, 1986). One of the most prominent tools that emerged to capture such time varying variances was the Generalized Autoregressive Conditional Heteroskedasticity $(\mathrm{GARCH})(\mathrm{Bollerslev}$ et al., 1992).The GARCH approach assumes that there is no shift in volatility; however, in such emerging markets there may potentially be sudden shifts in volatility. It is therefore important to take into account these shifts in estimating volatility persistence. Volatility is considered highly persistent if a shock to a given system is permanent. Historical volatility can be used in constructing forecasts of future volatility. However, tranquil periods where prices are more or less stable could be followed by relatively high volatility periods characterized by large price changes due to economic, political and/or social events, both regionally or globally. In this study, a great interest was focused on the effect of sudden volatility changes on the stock price levels of a small emerging Middle East stock market, namely, Jordan's Stock Market. This study is concentrated on Amman Stock Exchange (ASE) Composite Index and its five sector indices. Study covers the period aftermath the U.S. led war to Iraq in 2003 and its negative impact on Jordan's economy, and the 2007 global financial crisis and its implications on Jordan's economic development. Studies pertained the effect of aforementioned incidents and their effect in volatility on the efficiency of Middle East 
emerging stock markets during these crises were scarce and did not receive much attention. This research is intended to examine the effect of sudden shifts in unconditional variance of the indexes of five Jordanian general indexes on the efficiency of ASE market. With the similar purpose, the effect on the risk-returns relationship in ASE market was also analyzed. These sudden changes in volatility were identified endogenously using the GARCH, GARCH-M, and GARCH-DCC Models in addition to the iterated cumulative sums of squares (ICSS) algorithm developed by Inclan and Tiao in 1994. However, to our knowledge, this approach has not been employed in research works pertaining to Jordan's stock market, particularly in investigating the effect of large sudden shifts of volatility on the performance of the market.

\section{Previous Studies:}

Wang. And Mooreb, T. investigated the sudden changes in volatility in the stock markets of new European Union (EU) members by utilizing the iterated cumulative sums of squares (ICSS) algorithm. Using weekly data over the sample period 1994-2006. They found that a sudden change in volatility seems to arise from the evolution of emerging stock markets, exchange rate policy changes and financial crises. Elshareif et,al analyzed the behavior of Malaysian stock market during the intervals of high uncertainty. It highlighted the impact of unexpected volatility shifts on this small emerging Asian market, in terms of its efficiency and returns, during the past two decades; The purpose of this study was achieved through the Iterated-Cumulative-Sum-of-Squares-in-Volatility model; empirical results indicated the rejection of Efficient Market Hypothesis for the market when sudden volatility shifts were considered. The results also provided significant empirical evidences for positive risk-return relationship in the exchanges. In addition, the stock market was found to be more sensitive to global than local events (Elshareif,E.,et.al, 2012). The asymmetrical responses to good and bad news were also part of the market behavior. Researchers studied Asian stock markets during the intervals high uncertainty highlighted the impact of unexpected volatility shifts on the emerging Asian market, in terms of its efficiency and returns, during 1990-2011. The empirical results revealed a rejection of Efficient Market Hypothesis for the market when sudden volatility shifts were considered. However, significant empirical evidences for positive risk-return relationship in the exchanges and the stock market was found to be more sensitive to global than local events (Elshareif,E., et.al,2012).In a recent study, Kang et al have investigated five Central European stock markets. According to their empirical estimations, when sudden shifts of volatility were included in the GARCH model, the persistence of volatility was reduced significantly in each of the five markets. Based on the results, they have suggested that many previous studies may have overstated the degree of volatility persistence in financial time series, and highlighted the importance of capturing volatility shifts in the model(Kang et al. 2009).Studies on major markets like the London and New York stock exchanges, the evidence was in favor of the EMH, especially at the weak and semi-strong form levels (Fama, 1991).However, emerging markets, on the other hand, indicate significant departures from the Efficient Market Hypothesis (Omet et al., 2002). Adrian, $\mathrm{T}$ and Rosenberg,J explored cross sectional pricing of volatility risk by decomposing equity market volatility into short and long run components. Their study found out that prices 
of risk are negative and significant for both volatility components (Adrian,T and Rosenberg J, 2008) . Kang et al have investigated five Central European stock markets. Based on the results, they have suggested that many previous studies may have overstated the degree of volatility persistence in financial time series, and highlighted the importance of capturing volatility shifts in the model (Kang et al. 2009). Dash and Mallick have examined whether contagion effects exist on Indian stock market, during the current financial crisis originated from the US. Their empirical findings showed that there has been a significant increase in the mean of correlation coefficient between the markets in the crisis periods compared to the pre-crisis period. This proves the existence of contagion between the US and Indian markets and urges to find the channels of the contagion effect (Dash,A and Mallick,H,2010).Felder,R. analyzed the stock returns volatility and predictability for seven markets; he found out that the emerging markets have higher volatility yet lower persistence of shocks than immature markets. He also found out that the impact of non-trading days on volatility of emerging market stock returns is greater than that of mature markets (Richard A. Michel Felder, 2005). Pastor, L and Stambeugh, $\mathrm{R}$ in their study attempted to find out if the stocks are really less volatile in the long run. In contrast to annualized volatility of stock returns being lower conventionally in the long horizons due to mean reversion they found out that the stocks are substantially more volatile in the long run. They also proved that mean reversion contributes strongly to reducing long term variance but it is more than offset by various uncertainties (Pastor,L and Stambeugh,R, 2011).

\section{Data and Methodology}

\subsection{Data}

Data employed by this study was collected from ASE Files and consists of monthly indexes: General, Banks, Insurance, Services, and Industrial. Monthly data were chosen to avoid the potential biases associated with micro-structural issues, non-trading, the bid-ask spread effect in daily data, and problems of thin trading which were often associated with most emerging markets. All stock prices series were collected from Data Stream and spanned from Jan. 2004 to Dec. 2012, which includes the Global Financial Crisis. (Campbell et al., 1997).

Stock market returns were calculated according to the following formula:

$\mathrm{Rt}=(\log$ st- $\log \mathrm{st}-1) \times 100 \%$, Where: Rt is the market return, st, st-1 were the natural logarithms of the index at time (month) $t$ and $t-1$. Dividends were neglected.

\subsubsection{Research Problem}

Volatility is defined as the amount of uncertainty about the magnitude of changes in a security's value. Statistically it is the measure of the distortion of returns for a given security or market index. It can be measured by using the standard deviation or variance between returns from that same security or market index. This research problem is concerned on whether volatility has an effect on the efficiency of developing stock markets; in particular this research is intended to answer the following questions:

Is there a significant effect of volatility on indexes of ASE sectors? 
Is there a significant effect of volatility on ASE composite index?

\subsubsection{Research Hypotheses}

HO 1: There is no significant effect of volatility on ASE sectors indexes, at $\alpha \leq 0.05$.

HO 2: There is no significant effect of volatility on ASE composite index, at $\alpha \leq 0.05$

\subsection{Methodology}

Economic and financial time series typically exhibit time varying conditional standard deviations and correlations. The conditional standard deviation is also called the volatility. Higher volatilities increase the risk of assets, and higher conditional correlations cause an increased risk in portfolios. There are three main purposes of forecasting volatility, for risk management, for asset allocation, and for taking bets on future volatility. Therefore, models of time varying volatilities and correlations are essential for risk management (Reider,R., 2009). The volatility of a time series $\mathrm{Y} 1, \mathrm{Y} 2 \ldots$ at time $\mathrm{n}$ is the conditional standard deviation of Yn given Y1... Yn-1.

A characteristic feature of economic and financial time series is volatility clustering where periods of high and of low volatility occur in the data. Typically, the changes between periods of low, medium, and high volatility do not exhibit any systematic patterns and seem best modeled as occurring randomly. As financial asset returns evolve, they tend to move together. Their respective volatilities also tend to move together over time, across both assets and markets.

\subsection{GARCH models}

Modeling a time varying conditional covariance matrix, referred to as the volatility matrix, is important in many financial applications, including asset pricing, portfolio selection, hedging, and risk management(Palm,F.C.,1996).GARCH (Generalized Autoregressive Conditional Heteroscedastic) processes are dynamic models of conditional standard deviations and correlations. ARCH models have been developed to account for empirical regularities in financial data. Many financial time series have a number of characteristics in common:

Asset prices are generally nonstationary, return series show little or no autocorrelation, volatility of return series are clustered, the presence of unconditional excess kurtosis in the series could be related to the time variation in the conditional variance, some series exhibit leverage effects, and volatilities of some securities move together indicating certain linkages between markets(Black,1976). This tutorial begins with univariate GARCH models of conditional variance, including univariate APARCH (Asymmetric Power ARCH) models that feature the leverage effect often seen in asset returns. The leverage effect is the tendency of negative returns to increase the conditional variance more than do positive returns of the same magnitude. Multivariate GARCH models potentially suffer from the curse of dimensionality, because there are $d(d+1) / 2$ variances and covariances for a $d$-dimensional process, but most multivariate GARCH models reduce the dimensionality in some way. In examining the volatility behavior of the Jordan's stock market, it is observed that all stock prices exhibited high fluctuation which was followed by relatively low fluctuation in several 
periods. In addition, it was found that several structural breaks, outliers, extreme observations were mostly associated with sudden changes in unconditional variance in the sample period (Glosten, L.R., et al, 1993)

\subsubsection{GARCH model}

Having identified the change points in variance, the GARCH model is estimated without and with sudden changes in variance. The standard GARCH $(1,1)$ model can be

defined for the case without sudden changes as given

$$
\begin{gathered}
\mathrm{x}_{\mathrm{t}}=\mu+e_{t} \\
h_{t}=\omega+a e_{\mathrm{t}-1}^{2}+B h_{\mathrm{t}-1}
\end{gathered}
$$

$N$ represents the conditional normal density with mean zero and variance $h_{\mathrm{t}} \cdot I_{t-1}$ is the information available at $t$ - 1 . If some series show evidence of autocorrelation, then AR(1) with GARCH $(1,1)$ is estimated. The GARCH model with sudden changes can be modified as

$$
\begin{gathered}
\mathrm{x}_{\mathrm{t}}=\mu+e_{t} \\
h_{t}=\omega+\mathrm{d}_{1} \mathrm{D}_{1}+\ldots \ldots+\mathrm{d}_{\mathrm{n}} \mathrm{D}_{\mathrm{n}}+a e_{\mathrm{t}-1}^{2}+B h_{\mathrm{t}-1}
\end{gathered}
$$

Where $n D \ldots . . D 1$ are the dummy variables: 1 for each point of sudden change of variance onwards and 0 for otherwise. It is argued that the standard GARCH model overestimates the persistence in volatility since relevant sudden changes in variance are ignored

(Lastrapes, 1989 and Lamoreux and Lastrapes, 1990). The persistence of volatility, i.e. is predicted to be smaller than that found by the conventional GARCH model.

\section{Study results}

Table (1) Descriptive Statistics of Volatility and ASE returns series

\begin{tabular}{|l|l|l|l|l|l|l|}
\hline & VOLATILITY & BANKS & INSURANCE & SERVICE & INDUSTRY & GENERAL \\
\hline Mean & 0.860071 & 3.868205 & 3.513823 & 3.273571 & 3.430074 & 3.638842 \\
\hline Maximum & 1.670000 & 4.281397 & 3.886829 & 3.563955 & 3.948070 & 3.980140 \\
\hline Minimum & 0.390000 & 3.298198 & 3.078094 & 2.999131 & 2.876218 & 3.124178 \\
\hline Std. Dev. & 0.420473 & 0.312068 & 0.247129 & 0.174900 & 0.338326 & 0.286252 \\
\hline Skewness & 0.492107 & -0.611808 & -0.784986 & -0.031547 & -0.154472 & -0.560173 \\
\hline Kurtosis & 2.175932 & 2.137566 & 2.519378 & 1.968208 & 2.108712 & 2.078606 \\
\hline $\begin{array}{l}\text { J-B } \\
\text { p-value }\end{array}$ & $\begin{array}{l}0.961197 \\
(0.618413)\end{array}$ & $\begin{array}{l}1.307267 \\
(0.520152)\end{array}$ & $\begin{array}{l}1.572556 \\
(0.455537)\end{array}$ & $\begin{array}{l}0.623336 \\
(0.732224)\end{array}$ & $\begin{array}{l}0.519074 \\
(0.771409)\end{array}$ & $\begin{array}{l}1.227417 \\
(0.541340)\end{array}$ \\
\hline
\end{tabular}

This study adopts data from Amman Stock Exchange (ASE) and research period from 1999 to 2012. The main purpose in this study tries to find the relationship between volatility and stock returns. Table 1 is six variables' descriptive statistics and finds all variables are normally distributed because J-B ratio are significant. According to Kurtosis all variables appear leptokurtic phenomena. 
Table 2. Results of GARCH $(1,1)$ to run the regression of volatility with stock returns

\begin{tabular}{|c|c|c|c|c|c|}
\hline Sector & Parameters & Coefficient & Std Error & Z-statistics & $\mathrm{p}$-value \\
\hline \multirow{5}{*}{ Banks } & Mean & 0.571314 & 0.188935 & 3.023864 & 0.0025 \\
\hline & Constant & 3.370631 & 0.151274 & 22.28165 & 0.0000 \\
\hline & $\operatorname{ARCH}\left(\alpha_{1}\right)$ & -0.339449 & 0.666752 & -0.509109 & 0.6107 \\
\hline & $\operatorname{GARCH}\left(\beta_{1}\right)$ & 1.063864 & 1.540817 & 0.690455 & 0.4899 \\
\hline & $\left(\alpha_{1}+\beta_{1}\right)$ & 0.724415 & & & \\
\hline \multirow{5}{*}{ Insurance } & Mean & 0.535057 & 0.154702 & 3.458622 & 0.0005 \\
\hline & Constant & 3.087372 & 0.115894 & 26.63960 & 0.0000 \\
\hline & $\operatorname{ARCH}\left(\alpha_{1}\right)$ & -0.196618 & 0.372713 & -0.527532 & 0.5978 \\
\hline & $\operatorname{GARCH}\left(\beta_{1}\right)$ & 0.821978 & 1.180538 & 0.696274 & 0.4863 \\
\hline & $\left(\alpha_{1}+\beta_{1}\right)$ & 0.62536 & & & \\
\hline \multirow{5}{*}{ Service } & Mean & 0.337538 & 0.060150 & 5.611642 & 0.0000 \\
\hline & Constant & 2.987676 & 0.066603 & 44.85804 & 0.0000 \\
\hline & $\operatorname{ARCH}\left(\alpha_{1}\right)$ & -0.390945 & 0.618537 & -0.632048 & 0.5274 \\
\hline & $\operatorname{GARCH}\left(\beta_{1}\right)$ & 0.680112 & 2.229198 & 0.305093 & 0.7603 \\
\hline & $\left(\alpha_{1}+\beta_{1}\right)$ & 0.289167 & & & \\
\hline \multirow{5}{*}{ Industry } & Mean & 0.525606 & 0.178963 & 2.936959 & 0.0033 \\
\hline & Constant & 3.007220 & 0.110131 & 27.30576 & 0.0000 \\
\hline & $\operatorname{ARCH}\left(\alpha_{1}\right)$ & -0.473283 & 0.477907 & -0.990325 & 0.3220 \\
\hline & $\operatorname{GARCH}\left(\beta_{1}\right)$ & 0.504045 & 1.021303 & 0.493532 & 0.6216 \\
\hline & $\left(\alpha_{1}+\beta_{1}\right)$ & 0.030762 & & & \\
\hline \multirow{5}{*}{ General } & Mean & 0.590224 & 0.097174 & 6.073914 & 0.0000 \\
\hline & Constant & 3.147592 & 0.108546 & 28.99777 & 0.0000 \\
\hline & $\operatorname{ARCH}\left(\alpha_{1}\right)$ & -0.363649 & 0.759259 & -0.478952 & 0.6320 \\
\hline & $\operatorname{GARCH}\left(\beta_{1}\right)$ & 0.827279 & 1.280497 & 0.646061 & 0.5182 \\
\hline & $\left(\alpha_{1}+\beta_{1}\right)$ & 0.463630 & & & \\
\hline
\end{tabular}

The results presented in Table 2 show that there is a significant effect of present volatility on ASE stock returns at 5\% significant level for all individuals and general indices, the coefficient of the ARCH effect $(\alpha 1)$ is not statistically significant at $1 \%$ significance level. This indicates that news about volatility from the previous $t$ periods has not any explanatory power on current volatility. Similarly, the coefficient of the lagged conditional variance $(\beta 1)$ is not significantly different from zero, indicating volatility is not clustering in ASE return series. The sum of $(\alpha 1+\beta 1)$ coefficients is less than unity, suggesting that shocks to the conditional variance are highly persistent. This implies that wide changes in returns will not tend to be followed by wide changes and mild changes tend to be followed by mild Changes. A major economic implication of this finding for investors of the ASE is that stock returns volatility does not occur in cluster and as it is not predictable.

\section{References}

Adrian, T., \& Rosenberg J. (2008). Stock Returns and Volatility: Pricing the Short-Run and Long-Run Components of Market Risk. The Journal of Finance, 63(6), 2997-3030. 
http://dx.doi.org/10.1111/j.1540-6261.2008.01419.x

Ambrosio, F., \& Kinniry,F. (2007). Stock Market Volatility Measures in Perspective. Vanguard Investment Counseling \& Research.

Bollerslev et al. (1992). Generalized Auto Regressive Conditional Heterscedastiity. Journal of Econometrics, 31(1986), 307-327. http://dx.doi.org/10.1016/0304-4076(86)90063-1

Campbell, J.Y., A.W. Lo, \& A.C. MacKinlay. (1997). The econometrics of nancial markets. Princeton University Press.

Connors, L. (2007). Historical Volatility: The Holy Grail Found?, Connors Research, LLC.

Dash, A., \& Mallick, H. (2010). Contagion Effect of Global Financial Crisis on Stock Market in India. Centre For Development Studies (CDS), Trivandrum-11, Kerala, India.

Elshareif et,al. (2012). Business Management Dynamics, 1(10), 58-66.

Engle \& Mezrich. (1996). Garch for Groups, Risk, August 1996, 36-40.

Engle RF., \& Ng. V. (1993). Measuring and Testing the impact of news on volatility. Journal of Finance, 48, 1749-1778. http://dx.doi.org/10.1111/j.1540-6261.1993.tb05127.x

Glosten, L.R., R. Jagannathan, \& D. Runkle. (1993). Relationship between the expected value and the volatility of the nominal excess return on stocks. Journal of Finance 48, 1779-1801. http://dx.doi.org/10.1111/j.1540-6261.1993.tb05128.x

Hammoudeh, S., Li, H. (2006). Sudden changes in volatility in emerging markets: the case of Gulf Arab stock markets. International Review of Financial Analysis.

Jegajeevan,S. (2009). Return Volatility and Asymmetric News Effect in Sri Lankan Stock Market, Economic Research Department, Central Bank of Sri Lanka, Staff Studies, 40(1\&2).

Kang, S. H., S. Kang, \& S. Yoon. (2009). Forecasting Volatility of Crude Oil Markets. Energy Economics, 31(1), 119-125. http://dx.doi.org/10.1016/j.eneco.2008.09.006

Mala R., \& Reddy M. (2007). Measuring Stock Market Volatility in an Emerging Economy. International Research Journal of Finance and Economics, 8. Euro Journals Publishing Inc.

Marvides. (2003). Predictability and Volatility of stock returns. Managerial Finance, 29, 46-56.

Morana, C., \& Beltratti, A. (2002). The effects of the introduction of the euro on the volatility of European stock markets. Journal of Banking and Finance, 26, 2047-2064. http://dx.doi.org/10.1016/S0378-4266(01)00182-0

Omet et al. (2002). Efficiency tests and volatility effects: evidence from the Jordanian stock market. Appl. Econom. Letters, 9, 817-821. http://dx.doi.org/10.1080/13504850210161931

Parasuraman, N., \& Janaki Ramudu, P. (2011). Historical and Implied Volatility: An Investigation into NSE Nifty Futures and Options. Australian Journal of Business and Management Research, 1(7), 112-120.

Pastor, L., \& Stambeugh, R. (2011). Lubos Pastor and Robert F. Stambeugh. Are Stocks Less Volatile In The Long Run? (http://www.afajof.org/journal/forth_abstract.asp?ref=685).

Poshakwale, S., \& Murinde, V. (2001). Modelling the volatility in East European emerging 
stock markets: evidence on Hungary and Poland. Applied Financial Economics, 11, 445-456. http://dx.doi.org/10.1080/096031001300314009

Rajesh, T. 2010). Modelling volatility for the Indian stock market. The ICFAI Journal of Applied economics, $I X(\mathrm{I}), 79$.

Reider,R. (2009). Volatility Forecasting I: GARCH Models, The econometrics of nancial markets. Princeton University Press.

Richard A. Michel Felder. (2005). Volatility of stock returns: emerging and mature markets. Managerial Finance, 31(2), 66-86.

Schwert G.W. (1990). Stock Market Volatility. Financial Analysts Journal, May-June, 23-34. http://dx.doi.org/10.2469/faj.v46.n3.23

Uppal, J. (1998). Stock Return Volatility in an emerging market: A case study of the Karachi Stock Exchange. Managerial Finance, 24(3), 34-51. http://dx.doi.org/10.1108/03074359810765417 